tion be part of the treatment of anorexia nervosa? Even though only some patients show depletion of tissue zinc, all patients require zinc as they regain weight. In extreme cases of weight loss, or when patients fail to gain weight, supplementation is probably indicated. Zinc supplementation of subjects who are not deficient, however, may cause copper deficiency with anaemia and may impair immunity. At present, therefore, widespread treatment of anorexia nervosa with zinc is not indicated.

We are grateful to Professor A H Crisp, St George's Hospital Medical School, and Drs H A Oakeley and J P R Young, St Thomas's Hospital, for allowing us to study patients under their care. We thank the Wellcome Trust, the Stanley Thomas Johnson Foundation, and the special trustees of St Thomas's Hospital for support.

1 Casper RC, Kirschner B, Sandstead HH, Jacob RA, Davis JM. An evaluation of trace metals, vitamins and taste function in anorexia nervosa. Am $\mathcal{F}$ Clin Nutr 1980;33:1801-8.

2 Bakan R. The role of zinc in anorexia nervosa: etiology and treatment. Med Hypotheses 1979;5 731-6.

3 Bryce-Smith D, Simpson RID. Case of anorexia nervosa responding to zinc sulphate. Lancet 1985;i:1041-2.

4 Jones RB, Keeling PWN, Hilton PJ, Thompson RPH. The relationship between leucocyte and muscle zinc in health and disease. Clin Sci 1981;60:237-9.

5 Ferrante A, Thong YH. Optimal conditions for simultaneous purification of mononuclear and polymorphonuclear leucocytes from human blood by the Hypaque-Ficoll method. $\mathcal{f}$ Immunol Methods 1980;36:109-17.

(Accepted 16 fuly 1986)

Gastrointestinal Laboratory, Rayne Institute, St Thomas's Hospital, London SE1 7EH

C C AINLEY, MRCP, research fellow

J CASON, BSC, research officer

L CARLSSON, BSC, research office

R P H THOMPSON, DM, FRCP, consultant physician

Department of Chemical Pathology, St Thomas's Hospital, London SE1 7EH B M SLAVIN, FRCPATH, consultant chemical pathologist

Department of Psychiatry, St George's Hospital Medical School, London SW17

K R W NORTON, MRCPSYCH, lecturer

Correspondence to: Dr Ainley.

\section{Subacute encephalopathy associated with human immunodeficiency virus in haemophilia $\mathbf{A}$}

Neurological complications associated with the acquired immune deficiency syndrome (AIDS) have been well described in homosexuals and drug abusers but not in haemophiliacs. We report on two haemophiliacs who suffered fatal subacute encephalopathy after seroconverting to human immunodeficiency virus (HIV). This is a new manifestation of the disease as seen in haemophilia and has important implications.

\section{Case reports}

Case 1-A 25 year old man receiving regular treatment with factor VIII concentrate for severe haemophilia A developed anti-HIV antibody in 1981. In October 1985 he developed axillary lymphadenopathy, a polyclonal increase in immunoglobulin, lymphopenia with a low T4:T8 ratio, and weight loss. The diagnosis was AIDS related complex. In November he was admitted with a Streptococcus pneumoniae chest infection. Subsequently he complained of lethargy, poor concentration, and difficulty with micturition. Examination disclosed diminished cognitive function and brisk reflexes. Computed tomography (CT) of the brain showed dilated lateral ventricles and widened sulci consistent with cerebral atrophy. By March 1986 he was incontinent and had difficulty walking and showed signs of a pyramidal tract lesion. A myelogram was normal and lumbar puncture yielded no evidence of infection with bacteria, fungus, toxoplasma, herpes simplex, herpes zoster, cytomegalovirus, or papovavirus. Serological findings were negative for syphilis, hepatitis B, herpes virus, and cytomegalovirus. He remained positive for HIV antibody. One month later he was admitted unable to walk and with paranoid delusions. Relentless neurological deterioration followed with painful spastic quadriparesis and convulsions. He died in July after four months in hospital. Permission for a necropsy was refused.

Case 2-A 48 year old haemophiliac who had been treated with factor VIII concentrate developed anti-HIV antibody in March 1983. In July 1984 he was noted to have axillary lymphadenopathy, thrombocytopenia, and lymphopenia with a low T4:T8 ratio. AIDS related complex was diagnosed. Additionally, he had chronic persistent hepatitis as a legacy of non- $\mathrm{A}$, non-B hepatitis some years previously. He was admitted in August 1985 with weight loss, confusion, unilateral cerebellar dysfunction, and diplopia which was diagnosed clinically as an internuclear ophthalmoplegia. A cerebral CT scan showed low attenuation areas in the white matter of the frontal lobes and also in the right parietal lobe. Cerebrospinal fluid contained no evidence of infection by any of the agents sought in case 1 . Similarly, serology and blood culture gave no evidence of infection with any agent other than HIV. He continued to deteriorate and, having progressed to coma, died in October 1985. Permission for necropsy was refused.

\section{Comment}

Several neurological syndromes associated with HIV infection have been described in patients with AIDS and also in patients with AIDS related complex.

While an acute encephalopathy occurring as a reversible complication of primary HIV infection has been described in haemophilia $\mathrm{A},{ }^{2}$ fatal subacute encephalopathy has not been recognised as a risk for these patients. The probability that the aetiological agent in our patients was HIV is increased by reports that the virus is neurotropic and replicates in brain cells. ${ }^{3}$ Additionally, HIV is morphologically and genetically related to the visna virus, a neurotropic retrovirus affecting sheep and goats. ${ }^{3}$ The occurrence of subacute encephalitis and other neurological syndromes associated with HIV infection in haemophilia A casts doubt on the recently expressed hope that viral pathogenicity may have been attenuated during preparation of factor VIII concentrate. ${ }^{4}$

Several practical difficulties arose during the investigation and subsequent management of these two patients. Firstly, we were unable to find a laboratory willing to test for HIV antigen in the cerebrospinal fluid of either patient at the time of lumbar puncture. Secondly, the patients required three to four months of barrier nursing and terminal care in facilities usually reserved for acute admissions. In view of the potential number of patients at risk $^{5}$ we suggest that consideration should be given to providing supraregional laboratory and clinical facilities within the National Health Service for the diagnosis and management of syndromes associated with HIV.

We thank Mr S Rice and Mr J Bishop for the virology studies.

1 Snider WD, Simpson DM, Nieber $S$, et al. Neurological complications of acquired immune deficiency syndrome: analysis of 50 patients. Ann Neurol 1983;14:403-18

2 Carne CA, Tedder RS, Smith A, et al. Acute encephalopathy coincident with seroconversion for anti-HTLV-III. Lancet 1985; ii: 1206-8.

3 Black PM. HTLV-III, AIDS and the brain. N Engl f Med 1985;313:1538-40.

4 AIDS-Hemophilia French Study Group. Natural history of primary infection with LAV in multitransfused patients. Blood 1986;68:89-94

5 AIDS Group of the United Kingdom Haemophilia Centre Directors. Prevalence of antibody to HTLV-III in haemophiliacs in the United Kingdom. Br Med F 1986;293:175-6.

(Accepted 25 September 1986)

Department of Haematology, Royal Postgraduate Medical School, London W12 0HS

A RAHEMTULLA, BSC, MRCP, registrar

S T S DURRANT, MRCP, MRCPATH, senior registrar

J M HOWS, MRCP, MRCPATH, senior lecturer

Correspondence to: Dr Durrant.

\section{Hypothyroidism after treatment with ketoconazole}

I report on two patients, a father and his son, who both developed hypothyroidism after treatment with ketoconazole.

\section{Case 1}

This patient, a 40 year old white man, had had severe chronic mucocutaneous candidiasis since the age of 5 . The diagnosis had been confirmed by nail biopsy, and he had subsequently remained infected in the mouth, pharynx, larynx, oesophagus, and nails despite numerous and varied treatments, including treatment with vitamin B complex, dilute hydrochloric acid, and sodium thiosulphate in the 1950s; with dequalinium chloride paint, nystatin, amphotericin lotion and lozenges, and polynoxylin in the 1960s; and with intramuscular iron, clotrimazole, flucytosine, and miconazole in the 1970s. All of these treatments had been stopped because they were either ineffective or toxic.

In May 1982 he was given ketoconazole $200 \mathrm{mg}$ orally twice daily, which 